\title{
(Re)authoring the 27 club: Bewildered voices, acousmatic audiophilia and the dangers of listening-in
}

\author{
Ben Macpherson, University of Portsmouth
}

\begin{abstract}
This article considers the limits, layers and potential of vocal mimesis in the creation and performance of a new musical theatre work. Reflecting on the process and production of All That's Left - a musical that performed imagined conversations between pop-culture icons from 'The 27 Club'-I conceptualize voice as a plural space that connects imitation and originality by exposing, negotiating and re-siting the boundaries of mimetic vocality. Specifically, using Hillel Schwartz's The Culture of the Copy (2013) as a basis for discourse, I offer three readings of vocal mimesis as an act that constructs a space of plural and paradoxical possibilities. First, I consider the fidelity of timbral imitation or accent in 'singing like the celebrity', and use Frith (2008) in dialogue with Barthes's concept of the 'grain' (1977) to explore the paradox of vocal bewilderment in performing original versions of celebrities. Second, I reflect on the use of recorded voice, and draw on Chion (1999) and Sterne (2003) to suggest that acoumastic voice unveils the limits of mimesis while allowing a sonic (re)authoring in the process. Third, I consider the audience as transgressors (Connor 2004), and suggest that in listening-in to the ethereal and imagined thoughts of a longdeceased rock star, they themselves perform the very (re)authoring the mimetic voice itself offers.
\end{abstract}

\section{KEYWORDS}

Vocal mimesis

The 27 Club

Acousmatic audiophilia

Listening-in

Musical theatre

Imitation

\section{BIOGRAPHY}

Ben Macpherson is Senior Lecturer and Course Leader for Musical Theatre at the University of Portsmouth. He is co-editor of Journal of Interdisciplinary Voice Studies (Intellect) and co-editor of the Routledge Voice Studies book series, both with Konstantinos Thomaidis. Previous publications include the edited collection Voice Studies: Critical Approaches to Process, Performance and Experience (Routledge 2015), along with articles in Studies in Musical Theatre (Intellect), International Journal of Performing Arts and Digital Media (Routledge) and New Theatre Quarterly (Cambridge). Recent and forthcoming work on voice and musical theatre includes chapters for Oxford University Press and Routledge. For Palgrave, Ben is currently preparing a monograph entitled British Musical Theatre, 18901939: Imperialism and Identity (2017). As a composer, recent work includes All That's Left (2014). 


\section{INTRODUCTION: (RE)AUTHORING THE CELEBRITY}

In this article, I explore the limits, layers and potential of vocal mimesis. Conceptualizing the voice as a plural space that connects imitation and originality, I begin with a seemingly unrelated question posed by Rosemary J. Coombe in her book The Cultural Life of Intellectual Properties (1998: 88): 'Who authors the celebrity?' Using reflections on three specific aspects of the research and development of a new musical, this article aims to articulate one possible reply to Coombe's question through a focus on the vocal performance of celebrity.

In January 2014, I was commissioned by the New Theatre Royal Portsmouth to produce a short musical work developed with my undergraduate performing arts students, to be performed as part of the annual student drama festival. The commission was an ideal opportunity to enhance the burgeoning relationship between the theatre and the performing arts department of the University of Portsmouth's School of Media and Performing Arts. ${ }^{1}$ My co-writer and I had been working sporadically on a project for about eighteen months, and in an effort to catalyze its development, I suggested the piece to the commissioning producer, secured a director - a promising second-year undergraduate - and worked as MD and accompanist, along with her and a cast of six students (three male and three female). ${ }^{2}$ With a working title of All That's Left, the project explored the nature of celebrity and conspiracy by staging imagined conversations between members of The $27 \mathrm{Club}$ - the enigmatic group of popular musicians, poets and performers who all share the dubious privilege of having passed away aged 27, including performers such as Amy Winehouse (1983-2011). ${ }^{3}$ Working with a collection of half-notated songs, fragments of script, and assorted materials relating to Kurt Cobain (1967-1994; lead singer of 1990s grunge band Nirvana), Jim Morrison (1943-1971; lead singer of The Doors), Janis Joplin (1943-1970; American blues-rock singer), English World War One poets Rupert Brooke (1887-1915) and Isaac Rosenberg (1890-1918), and Alexander Bashlachev (1960-1988; Soviet era Russian punk poet), 'The 27 Club' became reframed as a members-only lounge in limbo, about which an extra-diegetic journalist had written an inaccurate coffee-table study based purely on second-hand evidence drawn from Wikipedia.

What became particularly fascinating during the development of the work, and as a partial answer to Coombe's opening question, was the nature of writing original material for such iconic celebrities in a process of (re)authoring them for the musical stage. In doing so, All 
That's Left opened the way for a consideration of the limits and layers of vocal performance; limits and layers that offer rich theatrical potential in the performance of real people on the musical stage.

\section{THE CULTURE OF THE COPY}

(Re)presenting well-known cultural figures on the musical stage is not new. Tribute acts are a popular form of entertainment, and the commercially successful 'bio-musical' format has gained popularity in recent years, with production such as Jersey Boys (2005), which tells the story of Franki Valli and the Four Seasons, or Beautiful: The Carole King musical (2014), offering a biographical depiction of a band or artist using their songs as dramatic or narrative punctuation. Often presenting hermetically-sealed narratives that claim to stage the 'true' (authentic) story of celebrity lives, 'bio-musicals' are performed by actors who carefully imitate the artist, with the production values all working alongside in order to evoke a sense of authenticity in the re-creation. ${ }^{4}$ Such a mimetic strategy operates on the basis of similarity between the imitation and the original. Yet, costuming or physical embodiment notwithstanding, of all the points of comparison, vocal similarity often forms the primary point of departure. ${ }^{5}$ To what extent the performer 'sounds like' the singer they are emulating therefore becomes the barometer of accuracy.

Echoing Platonic doctrine, sociologist Hillel Schwartz has noted that while any copy is inherently flawed, contemporary culture consumes replication in order to provide 'continuity, value, and authenticity', as seen in the popular consumption of tribute acts and 'bio-musicals', with the overt primacy of vocal imitation offering itself a site of evaluation (2013: 175). ${ }^{6}$ Yet, All That's Left was to be an original work, not a 'bio-musical'. Kurt Cobain would not be recognized through any shouted reference to 'teen spirit', and at no point would Jim Morrison laconically invite anyone to 'light his fire', in reference to popular songs by these musicians. The ability to offer continuity, value, and authenticity through immediate musico-vocal imitation was therefore different in this case. The ways in which this was negotiated and developed through the process proved provocative and yielded fascinating insights into the authoring of celebrity on the musical stage. Three aspects brought the layers, limits and potential of vocal performance into sharp focus in this regard: 1) the uses and problems of emulation and accent, 2) the distancing of voice from character, and 3) the ethics of stealing a character's voice in an act of eavesdropping. Reflecting on these areas and the strategies used 
in performance, the voice is found to be a place in and from which celebrities may be (re)authored and reinterpreted on the musical stage.

\section{THE USES AND PROBLEMS OF EMULATION AND ACCENT}

In her book The Human Voice, Anne Karpf (2006: 20) notes that there seems to be an inherent pre-occupation with accent, 'as if dialect and pronunciation made up the whole of the subject' of voice production. While many other anatomical, aural, oral, cultural and linguistic aspects combine in each unique voice, it is perhaps a truism that people are readily identifiable through accent and speech pattern. In this respect, in a later chapter of her book, Karpf considers the 'different vocal melodies' of countries, acknowledging certain characteristics that are broadly attributable to various regions and places (2006: 190).

A salient factor of celebrity identity can often be characteristics of the voice: Jim Morrison had notable vocal fry, while Robert Johnson appears to sound nasal and high-pitched in the few recordings available, albeit that these musicians_-and the poets Rupert Brooke and Isaac Rosenberg-were not known for their speaking voices. Yet, in an active display of encultured compulsion, the first workshop saw the cast automatically explore vocal emulation and imitation of the real-life figures they were (re)authoring in the piece. YouTube clips were played and verbatim monologues were developed, with much discussion of imitation and emulation as necessary to provide something for the audience in the absence of well-known songs from which they might deduce a sense of imitation of authenticity.

This sense of vocal imitation conferring continuity or attributing authenticity quickly became problematic, indicative of a particular limitation and subsequent possibility that we chose to exploit. As Roland Barthes suggests in his by-now ubiquitous text, no matter how much one voice tries to imitate another, emulation will always be limited by 'the materiality of the body speaking its mother tongue' (1977: 182). Even the best tribute act or impersonator will, in the end, never really sound like anyone but themselves - their vocal 'grain' betrays them. Vocal imitation - even through imitated 'vocal melodies' - therefore has its limits, meaning that any imitative quality can only exist and be experienced in relation to its own artifice (Karpf 2006: 190). Such limitations subsequently opened up possibilities for other aspects of vocal performance in the (re)authoring of these well-known celebrities. These possibilities are best articulated with reference to Simon Frith's sociological conception of the performing voice as a plural space of interpretive practice, constituting: 
- a musical instrument

- a body (echoing Barthes)

- a person

- a character

(Frith in Clayton 2008: 68)

While the students who performed as Jim Morrison, Janis Joplin, Robert Johnson and Kurt Cobain all assumed various iterations of a stereotypical 'general American' accent, and the voices developed for Rupert Brook and Isaac Rosenberg were mock-RP English, these broad cultural signifiers were the expressed limits of mimetic character in their vocal performance. Their use of voice as musical instrument was freed from subservience to well-known melodies in a performance of tribute or direct imitation, and as students learned new songs about Jim Morrison's allegedly spiritual encounter with the Navaho ('One Amerindian on the Roadside, Crying'), or MTV star Michelle Parma (1975-2002) sang about her career as a Dallas Cowboys Cheerleader ('Couldn't Make the Moon'), their vocal colours and intonation patterns remained their own: the actor playing Jim Morrison did not overly employ vocal fry in his dialogue (evident on many recorded interviews with The Doors' frontman), and the student who portrayed Janis retained her strong mezzo range without aspirate onset or twang.

In this sense, while vocal mimesis served to reference aesthetic or stylistic features, it was only one part of the voice as a plural site in performance. In fact, given the original nature of the musical material, the voice as 'musical instrument' would operate differently in this piece, re-authoring the musico-vocal expression in a new cultural space. Elsewhere in Schwartz's study of copies, he conceives of the potential relationship between a copy and its original through a devastating social observation about codependency: 'we use copies to certify originals, originals to certify copies, then we stand bewildered' (2013: 176). In other words, if imitation is the site of constructed continuity or authenticity, it only operates because of limits imposed by its 'bewildering', co-dependent dialogue with the original. This might be illustrated by the following diagram: 


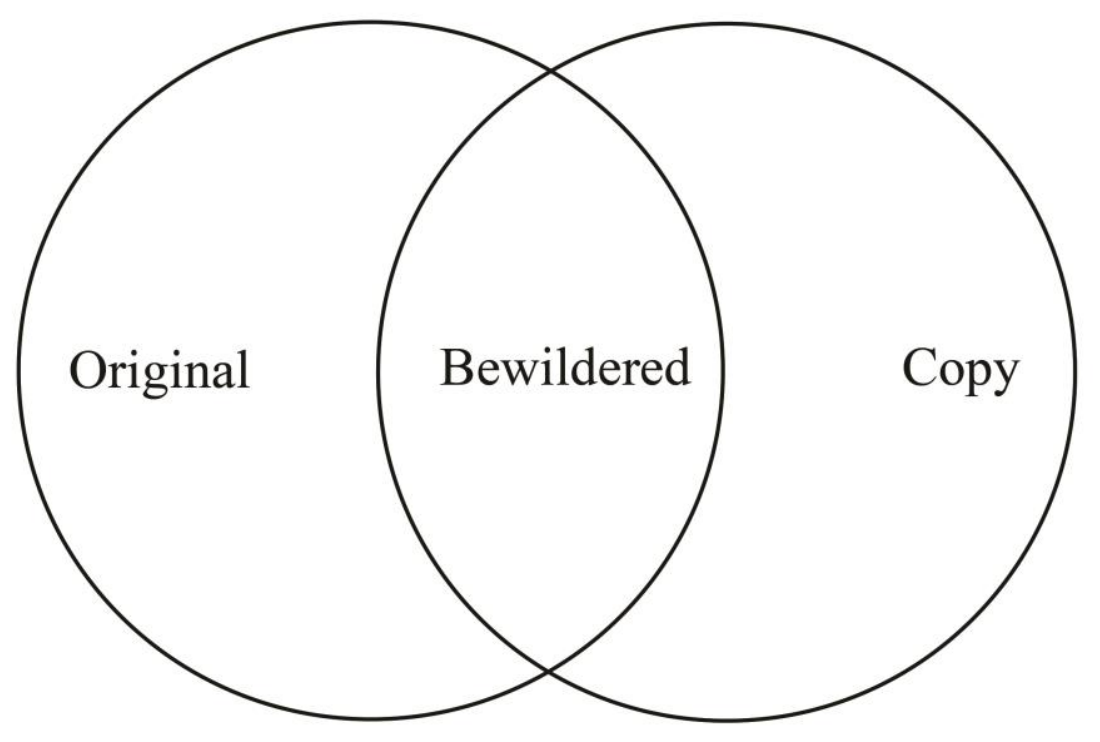

Figure 1. Schwartz's culture of the copy, diagram by Ben Macpherson.

This interrelationship between the original and the copy, and the sense of bewilderment wrought by a dialogue between them provides an interesting framework for considering the vocal performance of celebrity in All That's Left. With reference to the above discussion, a direction inclusion of Frith's vocal plurality into Schwartz's equation leads to the following expansion of the relationship between the original and the copy, articulating the potential limits and layers of vocal mimesis:

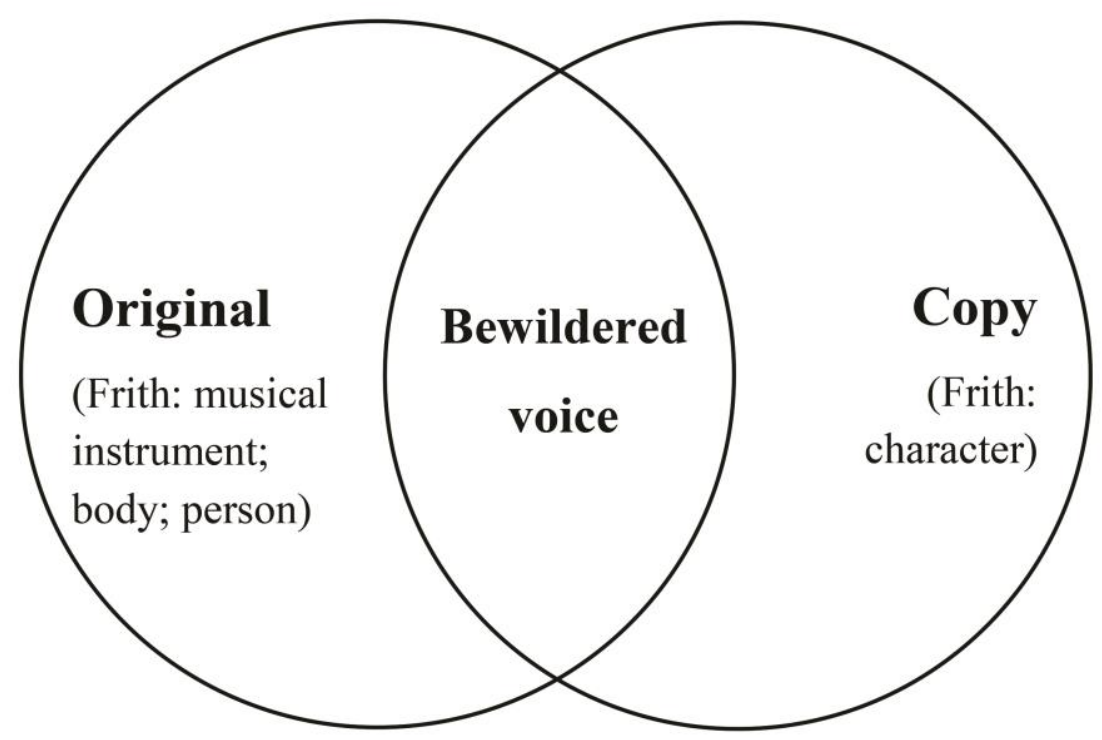

Figure 2. A culture of vocal mimesis, diagram by Ben Macpherson. 
In this iteration, the voice acts as a site which negotiates the limits of vocal mimesis as it seeks authorization within the context of an original musical score. Accent and visual cues invoke references to celebrities in the performance, but while Schwartz suggests that copies and originals ratify each other, the vocal mimesis finds its limits in the lack of original source material. The absence of a tangible 'original' produces what might be termed 'vocal bewilderment'; the voice can longer be a barometer of accuracy in judging the imitation, as the performers are (re)authoring celebrities through imitative affectation via the use of original material. The freedom this offers allowed such (re)authoring to explore these characters in new and exciting ways. Additionally, along with the limitations of vocal mimesis, the bewildered vocality also performed the distancing of voice from character.

\section{'BLACKVOICE': ACOUSMATIC AUDIOPHILIA AND THE DISTANCING OF VOICE FROM CHARACTER}

If the voice acts as a plural site for bewilderment, then any further inducement to audial anxiety through the distancing of the imitative voice from its subject would surely seem to complicate the nature of the copy and the attribution of continuity. In developing the character of Robert Johnson-the African-American musician whose style of blues guitar influenced a host of performers from B.B. King to Stevie Ray Vaughan-a simultaneous challenge and reinforcement of the relationship between the copy and the original occurred. Born in 1911, Johnson is seen as the elder statesman of The 27 Club in popular culture; a performer whose genius was gifted by the devil in a Faustian pact at the crossroads near Dockery Plantation Mississippi, and about whom little is known. A performance that explored The 27 Club would hardly have been complete without his character as a stalwart and backbone to the scenario we were trying to establish. However, at the time, there were no black students to assume this role, and having discounted blackface performance as a political and ethical strategy that would complicate the intentions of the work more than serve the dramaturgy, we began exploring the idea that Johnson's legacy was all-pervasive. His voice, therefore, would need to be more ethereal than that of more contemporary musicians and poets.

As Johnson was performing in the early twentieth century, during a period that saw much development in sound recording, we considered the idea of pre-recording the voice of Robert Johnson in order to evoke an era-specific technological advancement and a strong sense of 
'authenticity' in the mimetic representation of this character. Yet, already offering bewildered voices through the removal of original material with which the audience might validate these moments of (re)authoring, I was reminded of Adorno's sense of auditory distress over the identity of the recorded female voice without a body in 'The curves of the needle' ([1928] 1990). Considering Adorno's experience, Ella Finer has recently argued that the dislocation of voice from body complicates 'easy identification or characterization' (2015: 185), effecting a distancing of reception and resulting in what Michel Chion has defined as the acousmatic voice, leading to 'sounds one hears without seeing their originating cause' (1994: 71). In deliberately using recorded voice, were we further dislocating the connection between voice and celebrity? How might this impact the potential (re)authoring of Johnson?

The intention had always been for Johnson to be all-at-once ethereal and also strongly identifiable, and on this basis, I headed into a recording booth with an old, slightly out-oftune guitar, and with a 20-year-old white student from Basingstoke in Hampshire. In just two takes, we recorded a musicalized account of Johnson's Faustian encounter with Satan, called 'When The Devil Drives', along with several lines of dialogue spoken by Johnson. Once again, almost automatically, the student actor assumed a faux-Southern drawl, which we decided to retain for the recording, and to which we also added a vintage scratched vinyl effect as part of the post-production rendering. The voice of Robert Johnson had become a stereotype. Along with the recording effects, the patterning, inflections and accent in this performance were 'like' an old song performed by Johnson: Frith's vocal character was present. Yet, the voice was unmistakably the student's. His flat, short vowel sounds were present, the placement of his tongue overly-forward in his mouth when articulating was evident in the recording, and the over-pronunciation of various words betrayed the mimesis: 'was' became 'waws', 'devil' became 'devarl'. In short, this copy became 'black-voiced'; caught, bewildered between (stereotypical) imitation and (re)authoring.

However, rather than causing auditory distress through acousmatization as Finer, Adorno or Chion might reason, the dislocation of voice from source on the recording seemed to have the opposite effect. Joseph Sterne (2003) has suggested that the recorded voice may offer a different sense of embodied voice, rather than a dislocation, while Pieter Verstraete (2009: 227-32) has drawn on Jonathan Burston's discussion of 'fetishistic audiophilia' to suggest that the totalizing acousmatization of the voice in electronic form might create a new sonic materiality - one for which the audience might seek ratification but which leaves them 
bewildered. ${ }^{7}$ Verstraete continues his consideration of the way in which this new sonorous materiality 'gives the impression of having a life of its own, moving uncontrollably through space as an invisible, immaterial body that produces a direct, physical sensation on the listener' (2009: 228). This sensation is particularly powerful through electronic recordings, as Steven Connor has likewise noted: 'Recording makes listening transitive, and therefore powerful' (2014: 4). For Connor, the power in recorded voice is, in part, due to its acousmatic properties, but specifically as a result of the enforced active engagement by the listener.

If this recorded voice has a life of its own, this cannot be mimetic. This voice-pre-recorded, with an obvious digital effect, betraying the limits of its own mimetic character through accent-becomes a sonic materiality that explicitly resists categorization as a mimetic imitation, even when the student automatically attempted to emulate a stereotypical vocality of the genre concerned. It is simultaneously an imitative copy and an original. The acousmatized recorded voice ratifies itself, becoming its own authenticity as argued by Verstraete, and might be understood in this context with the phrase acousmatic audiophilia. This voice is the site of struggle: privileged, bewildered. For Ursula Bloom, such a state may (re)author the power of the voice, for she argues that it is the 'voice's distance from, rather than presence in, the body [its acousmatization] that constitutes the conditions of agency' (2007: 17). Indeed, this voice is a (sonic) copy of a (recorded) copy of a (mimetic) copy of a (mythological) copy - the popular lore of Johnson's pact; any 'original' source that Schwartz may wish to use for ratification is perpetually indeterminate. Yet, as Verstraete (2009) and Sterne (2003) have suggested, the very act of such mimetic indeterminacy assuming a new sonic materiality through recording allows it to become the focal point in an uncanny, dislocated performance of the limits of mimesis.

This focus, dislocation and bewilderment allowed for a (re)authoring of the Johnson myth in performance. Yet, in staging Johnson's song the stage director was keen that 'something should happen onstage'. Various suggestions were made throughout the first week as to what this should be, and eventually, a prop was selected to 'represent' Johnson's presence: an old rocking-chair was added to the performance space, on which sat a broken guitar. Scholars John Bell (1997) and Jody Joy (2009) have noted that the use of material objects to represent characters in performance bring with them a chain of associated socio-cultural meanings, and can act as material or referential metaphors, altering the configuration of distance or intimacy between character, performer, and audience. ${ }^{8}$ In this case, the chair did not become endowed 
with a persona; it remained a chair-the visual object representative of a character that was present in the space via a pre-recorded voice, which sonically 'bounced off' the legs, arms, back, seat and spokes, rather than becoming absorbed by them. The sense of disconnect between the visual and the vocal/aural was further reinforced by the activation of the object in performance. Scholar Penny Francis (2012: 18) has distinguished between objects that are configured as figures (personified or anthropomorphized) or objects (retaining their everyday materiality or function), suggesting that animated objects remain in their natural state, despite assuming the properties of the character represented, if manipulated or animated somehow. In the case of Robert Johnson, the performance of his song and dialogue was signified by a spotlight on the chair, as it was rocked by the foot of another performer. The chair's agency as a representative object was activated by other performers in a manner somewhat reminiscent of Tadeusz Kantor's description of puppets as poor objects, secondary onstage to the performer that activates them. The agency of the visual object was not even to act as a surrogate body: it was conceptually and performatively separate, maintaining the sense of disconnect and unrest that evoked the effervescence of the character. This reinforced the theatricality of the voice by denying it material agency, and allowed the plurality of the voice - as person, character, instrument and body - to become the primary focus as a dramatic agent through acousmatic audiophilia. In short, the material object endowed the voice with uncanny agency as a paradoxically imitative medium, mimetic at the point of the original.

Robert Johnson's voice was therefore experienced as a plural site between mimesis and materiality: a moment of new sonority through acousmatic audiophilia, found in the gaps and spaces between the material object (the rocking chair), the imitative medium (the recorded voice) and the audience's collusion in the uncanny paradox, which forced them to listen, 'straining toward a possible meaning' in the subtext and characterization, through the layers and limits of this bewildering voice (Nancy 2007: 2). Therefore, it is not only the performing voice involved in (re)authoring these celebrities, it is also the listening ears of the audience. When it came to giving voice - or the opposite - to Kurt Cobain, the bewildered voice did not perform a sense of aural negation between absence and fetishism but a sense of sadistic ambivalence evoking his legacy through the act of listening.

\section{EAVESDROPPING, STOLEN VOICES AND THE SADISTIC POWER OF LISTENING}


As the lead singer of 1990s Seattle grunge band Nirvana, Kurt Cobain's suicide note is widely available online. If it is genuine, it is tragic. If it is fake, it is also tragic. In either instance, one question pervaded the rehearsal room: how do you sing a suicide note? As a dramatic textwhether epistolary, linguistic or sung-its honesty and directness, along with the sheer sense of memory and regret, seemed to embody the conflict between personal demons and the hostages to celebrity and fame that many of those who died at 27 never negotiated successfully. This is not to romanticize the loss, pointlessness, brazen self-destruction, or otherwise nefarious circumstances that led to popular counter-cultural conspiracies and the mythology of a shared association and narrative between ultimately unrelated deaths; it does perhaps suggest the reason we were drawn to the subject as a potential music theatre project in the first place. Still, until the death of Amy Winehouse, Cobain was lauded in the popular press as the dominant icon of this counter-cultural community; making him sing was always going to be a problem. ${ }^{9}$

As a liminal artefact, the alleged suicide note left by Cobain was written when he was alive, and only read when he was deceased. As his last words, the intensity and intimacy in what would be the final song of the show led to a ballad in Ab major, with a simple chordal rhythm and piano-only accompaniment. In rehearsal, the student playing Cobain (who also played Richey Edwards from the Manic Street Preachers) really struggled to connect to the material in a meaningful way. 'It's too real—what if he actually wrote this?', he asked. During the process, the song was reassigned to the student playing Jim Morrison, who had also previously voiced Robert Johnson. In performing the suicide note as a song entitled 'Letter to an imaginary friend'-addressed to Cobain's imaginary childhood companion Boddahhands the letter to Jim Morrison. Singing these words, the cocksure front-man of The Doors, who spent much of the show championing the members of this club as immortal geniuses, is forced into his own vocal bewilderment. With the following first verse, the dramatic irony of Morrison's voice singing Cobain's words proved very interesting to develop:

I'D RATHER BE EMASCULATED.

I'D RATHER PLAY THE SIMPLETON, DON'T KNOW IT'S OVER, 


\section{'TIL IT'S GONE.}

\section{DIDN'T WANT TO DO THIS...}

In his paper 'Sadistic listening' (2004), Steven Connor considers a further crucial concept that relates to voice and its mimetic layers and limitations: the position of the listener. Connor discusses the sadistic subjectivity of the listener: 'one who installs themselves as the unheard hearer, the invisible addressee who alone can make sense of what is being said' (2009: 7). Citing psychoanalyst Theodore Reik's 1949 work Listening With The Third Ear, Connor observes the psychoanalytical imperative of resisting a patient's need for subjective interpretation, and the Freudian practice of removing the analyst from the visual field of the analysand. In short, the analyst becomes an eavesdropper on the subject's thoughts: 'What the eavesdropper hears with such handrubbing relish is the deafness of the speaker, and the power that such a fantasy of deafness gives' (Connor 2014: 7). Presumably, it was this sense of the deafness of the speaker that prompted the student to consider the poignancy of Cobain's alleged words. This form of eavesdropping appealed when it came to considering how we might make him sing, for in giving these words to Jim Morrison, the 'deafness of the speaker' (Connor 2014: 7) that the eavesdropping audience would hear is doubled: Cobain's voice did not speak his own words, and Morrison's voice speak words that are not his. Yet, is this eavesdropping? Or is this a form of aural voyeurism? Distinguishing between these acts, Johanna Linsley has suggested that the latter is directly related to sight and gratification, whereas eavesdropping allows the listener to create 'a history and persona for [the] subject' listened-in on (2015: 193). If the aural agency of eavesdropping allows the listener to create their own narrative - much like the popular press are wont to do with the lives and losses of these celebrities - then might this, in itself, suggest another limit (or layer) of vocal mimesis? Does the listener create their own copy, seeking to ratify it from an already-alienated position of indeterminacy?

As Salomé Voegelin has noted, hearing/listening is always flawed and full of doubt, without a meta-position from which to construct the discourse (2010: xii). In the case of this song, the absence of a meta-position is enhanced by Cobain's 'voice' being silenced (perhaps stolen?); Morrison's words are not his own, but they are words nonetheless. As such, their origin is questioned, exposed, cast into doubt. The copy has no origin; the limits of mimesis are exposed through a 'bewildered voice' assuming the character's agency, and the act of 
eavesdropping on Cobain's words becomes a moment in which the audience are forced to construct and question the many metanarratives and mythologies surrounding the contentious demise of Cobain. In short, the audience themselves may (re)author the celebrity through an act of sadistic listening to his bewildered, stolen voice.

\section{CONCLUSION}

This article began with Rosemary J. Coombe's question 'Who authors the celebrity?' (1998: 88). Considering the development of All That's Left and the possibilities of vocal performance, there are several responses that might be offered. The performance of voice as a plural site of negotiation between character and performer (after Frith) demonstrated the limits of vocal mimesis, while at the same time offering a sense of possibility beyond this in the performance of an original work.

Offering a tentative answer to her own question, Coombe suggests that: 'celebrity is authored in a multiplicity of sites of interpretive practice [...] mined for its symbolic resonances' (1998: 88-89). The multiplicity of sites includes the popular press, the music industry, copious fan community websites, and the consumption of ephemera by the populace. Notably, the voice appears to act as a repository for a 'multiplicity of sites' that perform the authoring of celebrities on stage. At least three sites, or layers, of authorship could be identified throughout the process. First, the use of accent allows a sense of imitation and 'continuity' of the celebrity image through vocal mimesis. However, the acceptance of the inescapable 'grain' exposes the limits of imitation. While an audience might use voice as a barometer of accuracy, the implicit acknowledgement that music-vocal performance in this context is always-already a heightened reality means that the performativity of the voice itself becomes a primary focus, with the potential for authoring the celebrity in a new way. In this sense, the celebrity may be authored by a 'bewildered voice'. Second, the use of recorded voice and the implicit acknowledgement of artifice may lead to acousmatic audiophilia, pushing even towards a 'present sense beyond sound' (Nancy 2007: 2), only to find that the audiophilia experienced acts as an agency to unveil the limits of mimesis; even uncanny mediation renders what is heard and how it is heard indiscernible, with the resultant bewildered voice still 'mined for its symbolic resonance' (Coombe 1998: 89).

Nevertheless, it is this sense of indiscernible agency, and the ineffability in performing the layers and limits of mimesis that provide a thrill, empowering singers and listeners, in the 
third layer of authorship, to eavesdrop on voices for which they cannot help but construct their own narrative: mimetic, flawed, and unknowable. Perhaps, in the end, the act of listening to these voices reformulates the flawed and unknowable listening-in that popular culture has taken so much pleasure in, creating mythologies so far away from reality that there is no original left to ratify. An accent suggests an origin, a recording embodies a sensibility, and a transgressive act of eavesdropping performs the very (re)authoring facilitated by the limits, layers and potential of vocal mimesis in musical theatre performance.

\section{REFERENCES}

Adorno, T.W. ([1928] 1990), 'The curves of the needle', (trans. T.Y. Levin.), October, 55: pp. 45-55.

Barthes, R. (1977), 'The grain of the voice', in Image, Music, Text, (trans. S. Heath), London: Fontana Press, pp.179-90.

Bell, J. (1997), 'Puppets and performing objects in the twentieth century', Performing Arts Journal 19: 2, pp. 29-46.

Bickerdicke, J.O. (2014), Fandom, Image and Authenticity: Joy Devotion and the Second Lives of Kurt Cobain and Ian Curtis, Basingstoke: Palgrave Macmillan.

Burston, J. (1998), 'Theatre space as virtual place: Audio technology, the reconfigured singing body, and the megamusical', Popular Music, 17: 2, pp. 205-18.

Chion, M. (1994), Audio-Vision: Sound on Screen, (trans. W. Murch and C. Gorbman), New York: Columbia University Press.

--- (1999), The Voice in Cinema, (trans. C. Gorbman), New York: Columbia University Press.

Connor, S. (2000), Dumbstruck: A Cultural History of Ventriloquism, Oxford and New York: Oxford University Press.

--- (2004), 'Sadistic listening', http://stevenconnor.com/sadisticlistening.html. Accessed: 3 May 2014.

--- (2015), 'Acousmania', http://stevenconnor.com/wpcontent/uploads/2014/09/acousmania.pdf. Accessed: 1 October 2015.

Coombe, R. J. (1998), The Cultural Life of Intellectual Properties: Authorship, Appropriation and the Law, Durham: Duke University Press.

Francis, P. (2012), Puppetry: A Reader in Theatre Practice, Basingstoke: Palgrave.

Finer, E. (2015), 'Strange objects/strange properties: Female audibility and the acoustic stage prop', in K. Thomaidis and B. Macpherson (eds.), Voice Studies: Critical Approaches 
to Process, Performance and Experience, Oxford and New York: Routledge, pp. 17787.

Frith, S. (2008), 'The voice as a musical instrument', in M. Clayton (ed.), Music, Words and Text: A Reader, Manchester: Manchester University Press, pp. 65-71.

Gross, K. (2011), Puppet: An Essay on an Uncanny Life, Chicago: University of Chicago Press.

Joy, J. (2009), 'Reinvigorating object biography: Reproducing the drama of object lives', World Archaeology, 41: 4, pp. 540-56.

Karpf, A. (2006), The Human Voice: How This Extraordinary Instrument Reveals Essential Clues about Who We Are, London: Bloomsbury.

Linsley, J. (2015), 'The eavesdropper: Listening-in and overhearing the voice in performance', in K. Thomaidis and B. Macpherson (eds.), Voice Studies: Critical Approaches to Process, Performance and Experience, Oxford and New York: Routledge, pp. 188-200.

Schwartz, H. (2014), The Culture of the Copy: Striking Likenesses, Unreasonable Facsimiles, Massachusetts: MIT Press.

Sounes, H. (2015), 27: A History of the 27 Club through the Lives of Brian Jones, Jimi Hendrix, Janis Joplin and Jim Morrison, Kurt Cobain and Amy Winehouse, Boston: Da Capo Press.

Taylor, M. (2012), Musical Theatre, Realism and Entertainment, Farnham, UK: Ashgate. Theodossopoulos, D. (2013), 'Laying claim to authenticity: Five anthropological dilemmas', Anthropology Quarterly, 86: 2, pp. 337-60.

Verstraete, P. (2009), 'The frequency of imagination: auditory distress and aurality in contemporary music theatre', Unpublished Ph.D. thesis, http://dare.uva.nl/document/2/65302. Accessed 15 September 2014.

\footnotetext{
ENDNOTES

${ }^{1}$ A public record of the festival might be found on Twitter: https://twitter.com/PompeyUniFest with the handle: @PompeyUniFest.

${ }^{2}$ I wish to thank the Faculty of Creative and Cultural Industries, and the School of Media and Performing Arts, for support in developing the research. In part, the piece was developed by means of institutional research funding to facilitate the project as a research-and-development activity, comprising the performance itself and the publication of concepts and issues arising from the process, as seen here. In particular, my colleague Matt Smith was of invaluable assistance in developing my thinking regarding puppetry and object theatre.

${ }^{3}$ For scholarship examining this popular cultural phenomenon, see Bickerdicke 2014 and Sounes 2015.

4 'Authenticity' is a complicated and much contested term that Demitrious Theodossopolous argues 'encompasses diverse sets of meaning that range from genuineness and originality to accuracy and
} 
truthfulness [...] It is concerned with [...] the authorship of products, producers, and cultural practices, the categorical boundaries of society: "who" or "what" is "who" or "what" claims to be" (2013: 339). The relationship to authorship and whether something or someone 'is' (or 'is like') what they claim is an appropriate definition with regards to this discussion.

${ }^{5}$ This explanation is necessarily quite reductive; the process is, in reality, far more nuanced and complex than space allows here. See Millie Taylor (2012: 152-56).

${ }^{6}$ On a broader level, the compulsion to 'make copies' was particularly pertinent in the case of The 27 Club, as the multitude of popular mythologies that have developed around these performers constantly re-author them in culture, and 'Best Of' albums provide a sense of continuity, keeping the performers 'alive' after their untimely demise. In many cases, all that is left of them is a recorded voice.

${ }^{7}$ See Burston 1999.

${ }^{8}$ The same is true of puppets, although not all object theatre is puppetry.

${ }^{9}$ Because of the recent nature of Winehouse's death, the decision was taken early on in the writing process not to include her in the narrative until the very end. In the course of developing the work, she was cut from the final performance altogether. 